\title{
Electrochromic and electrofluorochromic properties of a new boron dipyrromethene-ferrocene conjugate
}

Article

Accepted Version

Galangau, O., Fabre-Francke, I., Munteanu, S., DumasVerdes, C., Clavier, G., Méallet-Renault, R., Pansu, R.B., Hartl, F. and Miomandre, F. (2013) Electrochromic and electrofluorochromic properties of a new boron dipyrromethene-ferrocene conjugate. Electrochimica Acta, 87. pp. 809-815. ISSN 0013-4686 doi:

https://doi.org/10.1016/j.electacta.2012.09.048 Available at https://centaur.reading.ac.uk/30231/

It is advisable to refer to the publisher's version if you intend to cite from the work. See Guidance on citing.

To link to this article DOI: http://dx.doi.org/10.1016/j.electacta.2012.09.048

Publisher: Elsevier

All outputs in CentAUR are protected by Intellectual Property Rights law, including copyright law. Copyright and IPR is retained by the creators or other copyright holders. Terms and conditions for use of this material are defined in the End User Agreement. 


\section{CentAUR}

Central Archive at the University of Reading

Reading's research outputs online 
Elsevier Editorial System(tm) for Electrochimica Acta

Manuscript Draft

Manuscript Number: PK12-106R1

Title: Electrochromic and electrofluorochromic properties of a new boron dipyrromethene-ferrocene conjugate

Article Type: Research Paper

Keywords: boron dipyrromethene; ferrocene; electrochromic; fluorescence; redox switch

Corresponding Author: Dr Fabien MIOMANDRE,

Corresponding Author's Institution: ENS CACHAN

First Author: Olivier Galangau, Dr

Order of Authors: Olivier Galangau, Dr; Isabelle FABRE-FRANCKE, Dr; Sorin Munteanu; Cécile DUMASVERDES, Dr; Gilles CLAVIER, Dr; Rachel MEALLET-RENAULT, Dr; Robert PANSU, Dr; Frantisek HARTL, Pr; Fabien MIOMANDRE, Dr

Abstract: A new boron dipyrromethene-ferrocene (BODIPY-Fc) conjugate with pentafluorophenyl as the meso substituent and two Fc termini was synthesized and its spectroscopic and electrochemical features were analysed. An intramolecular charge transfer from the donor Fc to the acceptor BODIPY has been predicted by theory and confirmed experimentally, leading to efficient fluorescence quenching when the dyad is in the neutral state. Fluorescence can be triggered by oxidizing both ferrocenyl units either chemically or electrochemically. Eventually, a fully reversible fluorescence switch is evidenced by coupling TIRF microscopy with electrolysis in an electrochemical cell. 


\section{CNS \\ CACHA N}

\section{Photodinusique et Photochimie Supramoleculaires et Macromoleculares (PPSM)}

Tél. : 33 (0)। 47405338 ou 7709 - Fax : 33 (0)। 47402454

e-mail :

@ppsm.ens-cachan.fr

http://யwய.ppsm.ens-cachan.fr

Dear Editor,

I am pleased to send you the revised version of our paper submitted under the ref.PK12-106.

Here are the detailed reply to the reviewers comments :

Reviewer 1:

1. The oxidation of Bodipy (1) was checked again vs. ferrocene and confirms the value of table 1. Actually it is not surprising to have such a discrepancy for this compound, since Gaussian has trouble to deal properly with the geometry of the mesityl substituent in the calculations. The geometry optimization for BODIPY-mesityl gave a dissymmetrical structure with one styryl having a $15.8^{\circ}$ angle with the BODIPY core and the other a $23.6^{\circ}$ angle. This result was surprising and is probably not a good picture of the actual structure of the molecule. An alternate geometry where the mesityl groups were fixed at a 90。 angle was also tested but both geometries gave poor results for the electronic properties as seen on the orbitals energy and vertical absorption obtained by TDDFT. This point has been discussed in a previous paper (Org. Biomol. Chem., 2010, 8, 4546-4553).

2. Done in the revised form.

3. Fig 3b was simplified highlighting only the LUMO and HOMO orbitals instead of the whole set.

4. Unclear sentences have been corrected according to the reviewer's remark.

\section{Reviewer 2:}

1. Figure numbering was checked and corrected.

2. 'Microdisk' was changed into 'disk' as suggested.

3. The sentence was maintained since it concerns another kind of experiment (electrochemistry performed under fluorescence microscope) so the electrodes used are not exactly the same.

Reviewer 3 :

1. The electrode reactions have been added in the figure.

2. If this remark concerns the first oxidation process, we perfectly agree, but DPV allows to better separate the two steps of what appears as a shoulder in CV.

3. Even though these peaks are close to the limit of the potential window, it can be seen that the peak ratio between forward and backward signal is much less than one. This situation remains even if the potential is swept back a little bit earlier.

4. This was changed in the table and in the text.

5. Done in the revised form.

6. Done in the revised form.

7. Concentration of the supporting electrolyte was added. Potential values are not specified in the caption since the reference is only a pseudo-ref, so they may differ from those reported in table 2. Potentials are controlled by a thin layer CV recorded before spectroelectrochemical measurements.

\section{Best regards \\ Dr F. Miomandre}


Research Highlights

New boron dipyrromethene-ferrocene conjugate exhibiting electrochromic properties. Four redox states are available and investigated by spectroelectrochemistry. The fluorescence can be switched on by chemical or electrochemical oxidation. Fluorescence can be monitored reversibly under electrochemical control. 


\begin{abstract}
A new boron dipyrromethene-ferrocene (BODIPY-Fc) conjugate with pentafluorophenyl as the meso substituent and two Fc termini was synthesized and its spectroscopic and electrochemical features were analysed. An intramolecular charge transfer from the donor $\mathrm{Fc}$ to the acceptor BODIPY has been predicted by theory and confirmed experimentally, leading to efficient fluorescence quenching when the dyad is in the neutral state. Fluorescence can be triggered by oxidizing both ferrocenyl units either chemically or electrochemically. Eventually, a fully reversible fluorescence switch is evidenced by coupling TIRF microscopy with electrolysis in an electrochemical cell.
\end{abstract}

\title{
1. Introduction
}

The design of redox active fluorophores represents a very promising research field that has attracted much interest for a couple of years[1-6]. Practical applications in sensors of redox active compounds or in electrically driven light emitting devices can be envisaged. Among the various examples of such compounds described in the literature, ferrocene $(\mathrm{Fc})$ derivatives constitute the most popular family of redox-active moieties associated to fluorophores due to their redox stability and versatility of chemical functionalization[7-9]. Besides, boron dipyrromethene (BODIPY) is also one of the most encountered organic fluorophores because of its very convenient spectroscopic properties, namely strong UV-visible absorption, quite narrow fluorescence bands and corresponding high fluorescence quantum yields $\left(\Phi_{\mathrm{f}}>\right.$ 0.7)[10-13]. Nevertheless, only a few examples of BODIPY-ferrocene dyads have been

* Corresponding author : mioman@ppsm.ens-cachan.fr. Tel : 33147405339 ; Fax : 33147402454 
reported so far[14-17], despite their potentially interesting properties. Indeed, they are likely to display a low-lying intramolecular charge transfer (ICT) in the neutral form, as well as photoinduced electron transfer (PET) resulting in quenching of BODIPY-based fluorescence. These phenomena are likely to be cancelled upon changing the redox state of Fc, which has been demonstrated by chemical oxidation of other BODIPY-Fc conjugates $[14,15]$. In this communication, a new BODIPY-Fc compound with enhanced charge transfer between a donor mesityl styryl branch and an acceptor pentafluorophenyl meso substituent was synthesised and its electrochemical and spectroscopic properties were analysed in comparison with a model compound having the ferrocenyl termini replaced by mesityl groups (see Chart 1). Compared to previously published similar compounds, the difference arises from the meso substituent that is likely to enhance the attracting power of the BODIPY core in the final donor-acceptor-donor dyad. We will demonstrate that this compound represents an electrochemically controlled switch of fluorescence monitored by coupling TIRF microscopy and electrochemistry; this combination is known to be an efficient tool to highlight electrofluorochromism phenomena [18].
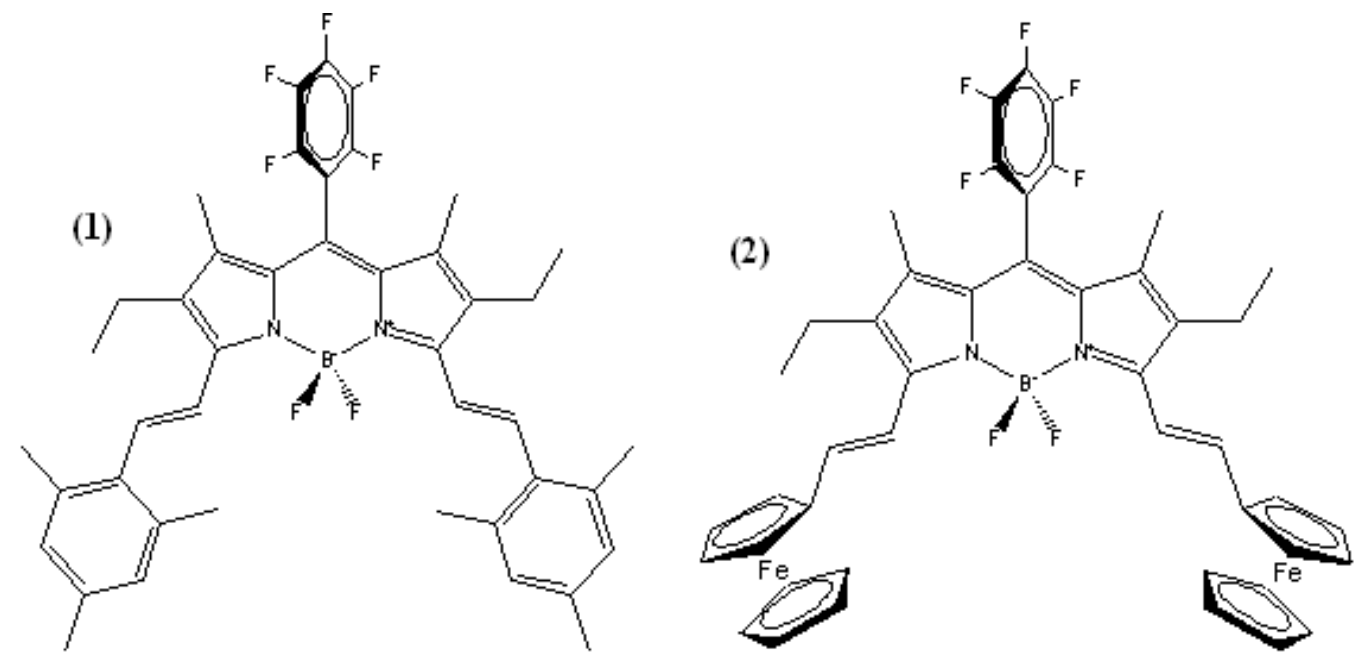

Chart 1 : The BODIPY-ferrocenyl (Fc) conjugate (2) and the reference compound BODIPYmesityl (1)

\section{Experimental section}

2.1 Materials and synthesis 
All reagents were purchased from Sigma-Aldrich and used as received. $\mathrm{CH}_{2} \mathrm{Cl}_{2}$ and petroleum ether were purchased from SDS and used as received. Toluene was distilled under $\mathrm{N}_{2}$ prior to use from sodium/benzophenone.

Column chromatography was carried out under positive pressure, using 40-63 $\mu \mathrm{m}$ silica gel (SDS) and the indicated solvents. Solvent evaporation was conducted under reduced pressure at temperatures lower than $45^{\circ} \mathrm{C}$. Further drying of the residue was accomplished under high vacuum.

NMR spectra were recorded on a JEOL ECS $400 \mathrm{MHz}$ spectrometer. FTIR analyses were carried out on a Nicolet Avatar 330 FTIR. Melting point was obtained without correction with a STUART SMP 10 apparatus. Liquid secondary ion high-resolution mass spectrometry data (HRMS) were obtained from the CRMPO mass spectrometry laboratory at the University of Rennes (France).

The synthesis of BODIPY-mesityl (1) has already been published by our group[19]. BODIPY-Fc (2) was synthesized according to the following procedure. Piperidine $(50 \mu \mathrm{L})$ was added to a solution of 8-pentafluorophenyl 1,7-dimethyl-2,6-diethyl-4,4-difluoro-4-bora3a,4a-diaza-s-indacene (209 $\mathrm{mg}, 0.44 \mathrm{mmol})$ in toluene $(30 \mathrm{~mL})$, under an argon atmosphere, followed by ferrocenecarboxaldehyde $(213 \mathrm{mg}, 0.99 \mathrm{mmol})$ in toluene $(10 \mathrm{~mL})$. The resulting mixture was refluxed for $30 \mathrm{~h}$. The solvent was removed under vacuum and the residue was purified by silica gel column chromatography, using $\mathrm{CH}_{2} \mathrm{Cl}_{2}$ :petroleum ether 2:8 (v/v) as the eluent. The blue fraction was collected to afford a dark blue solid (199 mg, yield 52\%). M.p. : 160-165 ${ }^{\circ} \mathrm{C}$. IR : $1606\left(v_{\mathrm{C}=\mathrm{C}}\right), 1497\left(v_{\mathrm{C}=\mathrm{N}}\right) \mathrm{cm}^{-1} .{ }^{1} \mathrm{H}$ NMR $\left(\mathrm{CDCl}_{3}, 400 \mathrm{MHz}\right) \delta 1.18(\mathrm{t}, \mathrm{J}=7.6$ Hz, 6H), 1.53 (s, 6H), 2.60 (q, J = 7.4 Hz, 4H), 4.24 (s, 10H), 4.46 (s, 4H), 4.66 (s, 4H), 7.20 $(\mathrm{d}, \mathrm{J}=16.6 \mathrm{~Hz}, 2 \mathrm{H}), 7.31(\mathrm{~d}, \mathrm{~J}=16.5 \mathrm{~Hz}, 2 \mathrm{H}) .{ }^{13} \mathrm{C} \mathrm{NMR}\left(\mathrm{CDCl}_{3}, 100 \mathrm{MHz}\right) \delta 151.3,137.8$, 135.9, 134.7, 117.3, 83.2, 70.7, 69.9, 68.2, 18.4, 14.3, 10.8. ${ }^{11} \mathrm{~B}^{\mathrm{NMR}}\left(\mathrm{CDCl}_{3}, 133 \mathrm{MHz}\right) \delta$ $0.26(\mathrm{t}, \mathrm{J}=34.5 \mathrm{~Hz}, 1 \mathrm{~B}) .{ }^{19} \mathrm{~F} \mathrm{NMR}\left(\mathrm{CDCl}_{3}, 376 \mathrm{MHz}\right) \delta 159.9(\mathrm{~m}, 2 \mathrm{~F}), 151.2(\mathrm{~m}, 1 \mathrm{~F}), 138.7$ (m, 4F). HRMS (electrospray): calculated for $\mathrm{C}_{45} \mathrm{H}_{38} \mathrm{~N}_{2} \mathrm{~F}_{7} \mathrm{~B}^{56} \mathrm{Fe}_{2}$ 862.1709, found 862.1726.

\subsection{DFT calculations}

Quantum chemical calculations were performed with the Gaussian 03 (Rev C.02) software[20]. Geometry optimizations were done at the B3LYP/Lanl2dz level of theory without symmetry constraint. In order to confirm the optimized structure is a true minimum, 
vibrational frequencies were calculated at the same level of theory when the geometry optimization was successful.

\subsection{Electrochemistry and spectroscopy}

Solvents (SDS, HPLC grade) and electrolyte salts (Fluka, puriss.) were used without further purification. Cyclic voltammetry was recorded in a three electrode cell with a potentiostat (CH Instruments 600) driven by a PC. Platinum or gold disks (1 mm diameter) were used as working electrodes, while a platinum wire and $\mathrm{Ag}^{+}\left(10^{-2} \mathrm{M}\right.$ in acetonitrile $) / \mathrm{Ag}$ were used as counter and reference electrodes, respectively. All the investigated solutions were deaerated by argon bubbling for at least $5 \mathrm{~min}$ before performing electrochemical measurements.

Electronic absorption spectra were recorded on a Cary 500 (Varian) spectrophotometer in 1 $\mathrm{cm}$ quartz cuvettes. Fluorescence spectra were recorded on a Fluorolog3 (Horiba) spectrofluorimeter, in a quartz cell at the right angle beam geometry. The solutions had OD below 0.1 at the excitation wavelength.

UV-vis spectroelectrochemistry at variable temperature was performed in an optically transparent thin layer electrochemical (OTTLE) cell[21] equipped with Pt minigrid working and auxiliary electrodes and a silver wire as a pseudoreference electrode. The BODIPY-Fc (1) solutions in dichloromethane freshly distilled from $\mathrm{CaH}_{2}$ contained pre-dried $3 \cdot 10^{-1} \mathrm{M}$ $\mathrm{Bu}_{4} \mathrm{NPF}_{6}$ (Aldrich) as the supporting electrolyte. The electrode potential during electrolyses was controlled by a PA4 potentiostat (Laboratory Devices, Polná, Czech Republic). The UVVis spectra were recorded on a SCINCO S-3100 photodiode array spectrophotometer.

\subsection{TIRF microscopy coupled to electrochemistry measurements}

The experimental setup used for these measurements has been described in more detail in a recent paper[18]. Briefly, it is based on the coupling of a three-electrode electrochemical cell with an epifluorescence microscope under excitation with either 515-nm laser pulses or white light and wavelength selection through filters. The working electrode is a very thin (ca. 25 $\mathrm{nm})$ Pt layer coated on a glass microscope slide (170 $\mu \mathrm{m}$ thin) on which the cell is stuck. Counter and pseudoreference electrodes are Pt and Ag wires, respectively. The setup allows simultaneous recording of the faradaic current and fluorescence intensity when applying a potential signal to the working electrode. The fluorescence intensity is recorded through a side 
port of the microscope and collected by a single photon photomultiplier or dispatched on a grating spectrometer for recording emission spectra under electrochemical control.

\section{Results and Discussion}

\subsection{Synthesis}

BODIPY-Fc (2) was synthesized according to the same procedure as reference BODIPYmesityl (1), viz. through a Knoevenagel-type condensation of ferrocenecarboxaldehyde with 8-pentafluorophenyl-2,6-diethyl-1,3,5,7-tetramethyl-4,4-difluoro-4-bora-3a,4a-diaza-sindacene in the presence of piperidine[19]. The $\pi$-extended BODIPY-Fc product was obtained in 52\% yield and characterized by multinuclear NMR, IR spectroscopy and mass spectrometry.

\subsection{Spectroscopy and electrochemistry}

Figure 1 displays the electronic absorption spectra of BODIPY-Fc (2) and the BODIPYmesityl (1) model compound as well as the luminescence spectrum of (1). The main absorption band of (1) in the visible region corresponding to the BODIPY chromophore is split into two bands in BODIPY-Fc (2); the additional absorption band in the red part of the visible spectrum $(739 \mathrm{~nm})$ can be ascribed to an ICT between the donor Fc and the acceptor BODIPY subunits, while the other one $(590 \mathrm{~nm})$ is mainly due to the BODIPY centred $\mathrm{S}_{0} \rightarrow \mathrm{S}_{1}$ transition, significantly blue shifted $(53 \mathrm{~nm})$ compared to (1). The bands in the UV region are ascribed to $\pi-\pi^{*} \quad \mathrm{~S}_{0} \rightarrow \mathrm{S}_{2}$ transitions located on the BODIPY backbone with additional contributions from $\pi-\pi^{*}(350 \mathrm{~nm})$ and metal centred d-d transitions $(430 \mathrm{~nm})$ located on the Fc subunits in (2)[22].

BODIPY-mesityl (1) emits light at $\lambda_{\max }=688 \mathrm{~nm}$ having the characteristic features of BODIPY fluorescence (i.e., high quantum yield, small Stokes shift)[19], while BODIPY-Fc (2) does not exhibit any emission. This behaviour is ascribed to an efficient PET between ferrocene (acting as a donor) and the excited state of BODIPY (acting as an acceptor).

Table 1 summarizes the spectroscopic features of both dyes.

$\underline{\text { Table } 1}$ : Spectroscopic data for compounds (1) and (2) in dichloromethane. 


\begin{tabular}{l|c|c|c|c|c} 
Compound & $\boldsymbol{\lambda}_{\max }^{a b s} \mathbf{1} / \mathbf{n m}$ & $\boldsymbol{\lambda}_{\max }^{a b s} \mathbf{2} / \mathbf{n m}$ & $\boldsymbol{\lambda}_{\max }^{a b s} \mathbf{3} / \mathbf{n m}$ & $\boldsymbol{\lambda}_{\max }^{e m} / \mathbf{n m}$ & $\begin{array}{c}\boldsymbol{\varepsilon}_{\boldsymbol{\lambda} \mathbf{1}}\left(\mathbf{x 1 0} \mathbf{1 0}^{\mathbf{3}}\right) \\
\mathbf{M}^{\mathbf{- 1}} \mathbf{c m}^{\mathbf{- 1}}\end{array}$ \\
\hline $\begin{array}{l}\text { BODIPY - } \\
\text { mesityl (1) }\end{array}$ & - & 643 & 364 & 688 & 54 \\
\hline BODIPY-Fc (2) & 739 & 590 & 342 & - & 30
\end{tabular}

Figure 2 displays the electrochemical behaviour of BODIPY-Fc (2) compared to the model BODIPY-mesityl (1). Three pairs of redox peaks can be identified in the cyclic voltammogram (CV) of (2) and unambiguously ascribed to monoelectronic reduction of BODIPY, poorly resolved bielectronic oxidation of $\mathrm{Fc}$ and monoelectronic oxidation of BODIPY going from the cathodic to the anodic electrode potentials. The anodic peak current ratios are in agreement with the respective number of exchanged electrons in each case. As can be seen in Table 2, the reduction of BODIPY is nearly unaffected by the presence of $\mathrm{Fc}$ moieties, because the added electron in both radical anions remains located on the BODIPY core (see the discussion on the LUMO below). As expected, the reduction potential is slightly less negative than reported for a similar compound lacking the pentafluorophenyl meso substituent[17]. Conversely, the oxidation of BODIPY occurs at a much more positive potential for (2) than for (1), due to the coulombic repulsion between the positive charge on the BODIPY core and those created when oxidizing $\mathrm{Fc}$ into ferrocenium $\left(\mathrm{Fc}^{+}\right)$. It seems also that the chemical stability of the fully oxidized BODIPY-Fc ${ }^{3+}$ species is lower than the one of oxidized BODIPY in (1) as shown by the smaller ratio of the backward vs. forward currents in the CV (this is confirmed by the spectroelectrochemical data, see below). Interestingly, the anodic wave corresponding to Fc oxidation in (2) is split into two components, as further evidenced by the differential pulse voltammetry (DPV) curve in Figure 2c. This feature corresponds to a mixed valence state in singly oxidized (2) that makes the second oxidation occur at a higher potential; this is the signature of a significant electronic interaction between the two Fc moieties in (2). While the first oxidation occurs nearly at the potential of free ferrocene (see Table 2), the oxidation of the second Fc moiety is positively shifted by $80 \mathrm{mV}$ (non-interacting redox centres normally display a difference of $35 \mathrm{mV}$ between their redox potentials[23]). The redox potential values for the Fc termini are found very close to those published for the parent compounds without the pentafluorophenyl meso substituent[17].

Table 2: Redox formal potentials for compounds (1) and (2) measured vs. ferrocene/ferrocenium 


\begin{tabular}{l|l|l|l} 
Compound & $\mathbf{E}^{\mathbf{0}}{ }_{\mathbf{1}} / \mathbf{V}$ & $\mathbf{E}^{\mathbf{0}} / \mathbf{V}$ & $\mathbf{E}_{\mathbf{3}}^{\mathbf{0}} / \mathbf{V}$ \\
\hline BODIPY-mesityl (1) & -1.33 & - & 0.47 \\
\hline BODIPY-Fc (2) & -1.32 & $0.05 ; 0.13$ & 0.75
\end{tabular}

\subsection{Molecular and orbital modelling}

The geometry of (2) was calculated using the DFT B3LYP optimization method (see Figure 3A). The pentafluorophenyl meso substituent is found almost perpendicular to the BODIPY core due to the steric hindrance of the methyl side groups. The vinyl bridges are almost in the same plane as the BODIPY (dihedral angle : $13^{\circ}$ ) and the cyclopentadienyl groups (dihedral angle $: 8^{\circ}$ ). These facts suggest that the conjugation between both ferrocenyl centres through the BODIPY core is facilitated by the geometry. Besides, both 'cis' and 'trans' configurations for the relative positions of the ferrocenyl groups are allowed, since the energy difference is small $(0.08 \mathrm{eV})$.

The orbital modelling of the 'trans' configuration of (2) is shown in Figure 3B. The LUMO is, as expected, mainly centred at the BODIPY core, although with a small contribution from the ferrocenyl termini. The conjugation is clearly predicted by the calculations when looking at the HOMO, since the electron density is spread over the whole molecule backbone and not confined only on the ferrocenyl moieties. Table 3 compares the energy levels obtained by the calculations with the ones derived from spectroscopic and electrochemical data. The calculated HOMO-LUMO gap for BODIPY-Fc (2) is close to that determined experimentally. However, it was difficult to find a satisfactory geometry for BODIPY (1) and its LUMO energy and thus HOMO-LUMO gap are therefore clearly overestimated. The dication of BODIPY-Fc (2) was also calculated. The single electrons are clearly distributed over both ferrocenyl units as expected from electrochemistry (see Fig. 3C).

$\underline{\text { Table } 3}$ : Calculated and experimentally deduced frontier orbital energies (eV).

\begin{tabular}{c|c|c|c|c} 
& Compound & DFT $^{\mathbf{i}}$ & $\begin{array}{c}\text { UV-Vis } \\
\text { Spectroscopy }\end{array}$ & Electrochemistry $^{\text {iii }}$ \\
\cline { 1 - 3 } LUMO & \multirow{3}{*}{ (1) } & -3.17 & - & -3.77 \\
\cline { 1 - 1 } $\begin{array}{c}\text { HOMO } \\
\text { gOp }\end{array}$ & & -5.19 & - & -5.57 \\
\cline { 3 - 5 } & & 2.02 & 1.92 & 1.80 \\
\hline
\end{tabular}




\begin{tabular}{|c|c|c|c|c|}
\hline LUMO & \multirow{3}{*}{ (2) } & -3.16 & - & -3.78 \\
\hline HOMO & & -5.11 & - & -5.15 \\
\hline $\begin{array}{c}\text { HOMO-LUMO } \\
\text { gap }\end{array}$ & & 1.95 & 1.67 & 1.37 \\
\hline Level of theory: & $I$ & & & \\
\hline
\end{tabular}

\subsection{UV-Vis spectroelectrochemistry}

The spectroelectrochemical behavior of BODIPY-Fc (2) was investigated in an optically transparent thin layer cell allowing rapid exhaustive electrolysis and outstanding resolution of close lying redox steps (Fig. 4). First, when a negative potential $\left(\mathbf{E}^{\mathbf{0}}{ }_{1}\right)$ is applied to generate the anion radical of (2) (Fig. 4a), one can clearly observe a dramatic drop of the intensity associated with the ICT band in the red part of the spectrum. Several isosbestic points as well as full recovery upon reoxidation give evidence that the electrochemical reduction leads to a single stable species under the experimental conditions. When applying a positive potential $\left(\mathbf{E}_{2}^{\mathbf{0}}\right.$ ) corresponding to the first oxidation (Fig. 4b), the ICT band intensity starts to fall down while a new band in the $600 \mathrm{~nm}$ range rises. There is also a small but significant band of the monocation rising at ca. $870 \mathrm{~nm}$, which probably corresponds to the $\mathrm{Fe}$ (II)-Fe(III) intervalence electron transfer (IVCT), for it again disappears when the dication is formed.

Sweeping the anodic potential to the second oxidation $\left(\mathbf{E}_{\mathbf{3}}^{\mathbf{0}}\right)$ makes the original ICT band totally vanish while a second new band just below $700 \mathrm{~nm}$ clearly appears. The latter has also a charge transfer character but now the BODIPY core acts as the donor and the ferrocenium moieties as the acceptors. This is confirmed by the disappearance of this band when the BODIPY is oxidized in its turn, but this final oxidation is not fully reversible, as expected from the CV (Fig. 2b). The results are consistent with those from similar compounds[16] but in the present case the signature of the three successive oxidized steps has been identified.

The anodic spectroelectrochemistry of (2) in dichloromethane was repeated at $243 \mathrm{~K}$. It resulted in a slightly different intensity pattern of the dication in the visible region and increased stability of the fully oxidized tricationic product.

\subsection{Electrochemical monitoring of the fluorescence}


It has already been demonstrated that in this kind of dyad the fluorescence can be switched on upon ferrocene oxidation[16]. First we checked this possibility by chemical oxidation using $\mathrm{FeCl}_{3}$ as the oxidizing agent. Figure 5 shows the evolution of the emission spectra recorded in a cuvette upon successive additions of $\mathrm{FeCl}_{3}$ when exciting at $590 \mathrm{~nm}$ (at this wavelength the absorption does not change upon oxidation, see Fig.4). A new emission band starts to appear at $610 \mathrm{~nm}$, in agreement with previously observed behaviour[15]. This fluorescence is associated with the absorption peak at $610 \mathrm{~nm}$ that rises in Fig.4d with a very small Stokes shift. To confirm this result, we tried to monitor the luminescence switch electrochemically instead of chemically. Having coupled TIRF microscopy with the electrochemical cell set-up, we were able to record the luminescence intensity modulation as a function of applied potential. Figure 6 shows that the luminescence of (2) can reversibly be switched between the emitting bielectronic oxidized state and the non-emitting neutral state. Increasing the positive potential limit makes the modulation faster and the amplitude greater. Note that the potentials are different from the ones determined by $\mathrm{CV}$ due to uncompensated ohmic drop in the TIRFM electrochemical setup (the working electrode area in the latter is larger). The two potential values applied at the end of the step correspond to oxidation of the Fc moieties while the BODIPY core remains neutral. It confirms that cancelling the donor character of the $\mathrm{Fc}$ moiety upon oxidation can actually restore the BODIPY fluorescence and that this process can be controlled reversibly. Finally the recording of emission spectra upon application of electrode potential shows an emerging band with a maximum near $610 \mathrm{~nm}$ that disappears when the potential is stepped back to 0V (Figure 7). This confirms that the electrogenerated emitting species is the same as in the chemical oxidation experiments. The reversibility proves that the luminescence does not come from residual BODIPY or BODIPY liberation upon oxidation of BODIPY-Fc (2). Thus it is demonstrated that (2) actually exhibits an electrofluorochromic behaviour between the neutral and bielectronic oxidized states.

\section{Conclusion}

A new dyad involving an organic fluorophore (BODIPY) connected to two redox-active moieties (ferrocenyl termini) has been synthesized and its electrochemical and spectroscopic features analysed with a support from theoretical modelling. In the dyad the two ferrocene units are conjugated with the BODIPY core, the fluorescence of which being totally quenched by a photoinduced electron transfer. It has been demonstrated that bielectronic oxidation of the termini to ferrocenium (either chemical or electrochemical) triggers the fluorescence of 
the BODIPY chromophore at $610 \mathrm{~nm}$. The process is fully reversible. Applications in the field

\section{Acknowledgments}

J.F. Audibert is warmly acknowledged for the TIRF microscopy measurements.

\section{References}

[1] A.C. Benniston, G. Copley, K.J. Elliott, R.W. Harrington, W. Clegg, Eur. J. Org.Chem., (2008) 2705.

[2] R.A. Illos, E. Harlev, S. Bittner, Tet. Lett., 46 (2005) 8427.

[3] H. Röhr, C. Trieflinger, K. Rurack, J. Daub, Chem. Eur. J., 12 (2006) 689.

[4] X.W. Xiao, W. Xu, D.Q. Zhang, H. Xu, L. Liu, D.B. Zhu, New J. Chem., 29 (2005) 1291.

[5] G.X. Zhang, D.Q. Zhang, X.F. Guo, D.B. Zhu, Org. Lett., 6 (2004) 1209.

[6] C. Dumas-Verdes, F. Miomandre, E. Lepicier, O. Galangau, T.T. Vu, G. Clavier, R. Meallet-Renault, P. Audebert, Eur. J. Org. Chem., (2010) 2525.

[7] R.L. Zhang, Z.L. Wang, Y.S. Wu, H.B. Fu, J.N. Yao, Org. Lett., 10 (2008) 3065.

[8] A. Togni, T. Hayashi, Wiley-VCH, Weinheim, 1995.

[9] M.J. Carney, J.S. Lesniak, M.D. Likar, J.R. Pladziewicz, J. Am. Chem. Soc., 106 (1984) 2565.

[10] A. Loudet, K. Burgess, Chem. Rev., 107 (2007) 4891.

[11] R. Ziessel, G. Ulrich, A. Harriman, New J. Chem., 31 (2007) 496.

[12] G. Ulrich, R. Ziessel, A. Harriman, Angew.Chem.Int.Ed., 47 (2008) 1184.

[13] A.C. Benniston, G. Copley, Phys. Chem. Chem. Phys., 11 (2009) 4124.

[14] T.K. Khan, R.R.S. Pissurlenkar, M.S. Shaikh, M. Ravikanth, J. Organomet. Chem., 697 (2012) 65.

[15] M.R. Rao, K.V.P. Kumar, M. Ravikanth, J. Organomet. Chem., 695 (2010) 863.

[16] X.D. Yin, Y.J. Li, Y.L. Li, Y.L. Zhu, X.L. Tang, H.Y. Zheng, D.B. Zhu, Tetrahedron, 65 (2009) 8373.

[17] R. Ziessel, P. Retailleau, K.J. Elliott, A. Harriman, Chem.Eur. J., 15 (2009) 10369.

[18] F. Miomandre, E. Lepicier, S. Munteanu, O. Galangau, J.F. Audibert, R. Meallet-Renault, P. Audebert, R.B. Pansu, ACS Appl. Mat. Int., 3 (2011) 690.

[19] O. Galangau, C. Dumas-Verdes, R. Meallet-Renault, G. Clavier, Org. Biomol. Chem., 8 (2010) 4546.

[20] R.C. Gaussian 03, M. J. Frisch, G. W. Trucks, H. B. Schlegel, G. E. Scuseria, M. A. Robb, J. R. Cheeseman, J. A. Montgomery, Jr., T. Vreven, K. N. Kudin, J. C. Burant, J. M. Millam, S. S. Iyengar, J. Tomasi, V. Barone, B. Mennucci, M. Cossi, G. Scalmani, N. Rega, G. A. Petersson, H. Nakatsuji, M. Hada, M. Ehara, K. Toyota, R. Fukuda, J. Hasegawa, M. Ishida, T. Nakajima, Y. Honda, O. Kitao, H. Nakai, M. Klene, X. Li, J. E. Knox, H. P. Hratchian, J. B. Cross, C. Adamo, J. Jaramillo, R. Gomperts, R. E. Stratmann, O. Yazyev, A. J. Austin, R. Cammi, C. Pomelli, J. W. Ochterski, P. Y. Ayala, K. Morokuma, G. A. Voth, P. Salvador, J. J. Dannenberg, V. G. Zakrzewski, S. Dapprich, A. D. Daniels, M. C. Strain, O. Farkas, D. K. Malick, A. D. Rabuck, K. Raghavachari, J. B. Foresman, J. V. Ortiz, Q. Cui, A. G. Baboul, S. Clifford, J. Cioslowski, B. B. Stefanov, G. Liu, A. Liashenko, P. Piskorz, I. 
Komaromi, R. L. Martin, D. J. Fox, T. Keith, M. A. Al-Laham, C. Y. Peng, A. Nanayakkara, M. Challacombe, P. M. W. Gill, B. Johnson, W. Chen, M. W. Wong, C. Gonzalez, and J. A. Pople, Gaussian, Inc., Wallingford CT, 2004.

[21] F. Hartl, H. Luyten, H.A. Nieuwenhuis, G. Schoemaker, Appl. Spectroscopy, 48 (1994) 1522.

[22] U.M. Rabie, Spectrochimica acta. Part A, Molecular and biomolecular spectroscopy, 74 (2009) 746.

[23] A.J. Bard, L.R. Faulkner, Electrochemical Methods: Fundamentals and Applications, in, Wiley, New York, 2001. 


\section{Figure captions}

Figure 1 : Electronic absorption spectra of (1) (blue full line) and (2) (red full line) and emission spectrum of (1) (blue dashed line, excitation : $640 \mathrm{~nm}$ ) in dichloromethane.

Figure 2 : CV of A) BODIPY-mesityl (1) and B) BODIPY-Fc (2) $1 \mathrm{mM}$ in dichloromethane $\left(+0.1 \mathrm{M} \mathrm{TBAPF}_{6}\right)$ on $\mathrm{Pt}$ (scan rate: $\left.50 \mathrm{mV} / \mathrm{s}\right)$. Potentials are vs. $\mathrm{Ag}^{+} / \mathrm{Ag}$ reference. Peak under the cross is not due to the compound.

C) : DPV of BODIPY-Fc (2) (pulse width : $50 \mathrm{~ms}$; pulse amplitude : $10 \mathrm{mV}$; scan rate : 5 $\mathrm{mV} / \mathrm{s})$

Figure 3 : A) Optimized geometries (left : 'cis' form ; right : 'trans' form) of BODIPY-Fc (2). B) Frontier molecular orbitals of (2). C) Spin density difference $(\operatorname{spin}(\alpha)-\operatorname{spin}(\beta))$ for the dication of BODIPY-Fc (2) (blue lobes correspond to excess $\alpha$ spin density)

Figure 4 : UV-vis spectroelectrochemistry of BODIPY-Fc (2) $10^{-3} \mathrm{M}$ in dichloromethane (+ $\left.0.3 \mathrm{M} \mathrm{TBAPF}_{6}\right)$ at $283 \mathrm{~K}$ (OTTLE cell). A) One electron reduction into the radical anion ; B) One-electron oxidation into the corresponding cation; $\mathrm{C}$ ): one-electron oxidation of the cation into the corresponding dication. D) Irreversible one-electron oxidation of BODIPY-Fc ${ }^{2+}$.

Figure 5 : Emission spectral changes $\left(\lambda_{\text {exc }}=590 \mathrm{~nm}\right)$ of BODIPY-Fc (2) $5.4 \mu \mathrm{M}$ in dichloromethane upon addition of $\mathrm{FeCl}_{3}$. The $\mathrm{FeCl}_{3}$ concentration was varied from 0 to 70 $\mu \mathrm{M}$ by $10 \mu \mathrm{M}$ steps.

Figure 6 : Simultaneous variations of fluorescence intensity (upper curve, left scale in a.u.) and current (lower curve, right scale in A) recorded under microscope upon potential steps between $-0.4 \mathrm{~V}$ and resp. $1.2 \mathrm{~V}$ (a) or $0.9 \mathrm{~V}$ (b) for $30 \mathrm{~s}$, for BODIPY-Fc (2) $1 \mathrm{mM}$ in dichloromethane. Excitation: laser pulse $(515 \mathrm{~nm})$.

Figure 7 : Emission spectroelectrochemistry of BODIPY-Fc (2): $0.2 \mathrm{mM}$ in acetonitrile, recorded under fluorescence microscope, using TIRF illumination, at various electrolysis times (reversal time : 30s). Electrode potential : $1 \mathrm{~V}$ vs. Ag pseudoreference electrode. Excitation: white mercury lamp with FITC filter (460-500 nm).

Figure SI1 : UV-vis spectroelectrochemistry of BODIPY-Fc (2) $10^{-3} \mathrm{M}$ in dichloromethane dichloromethane $\left(+0.3 \mathrm{M} \mathrm{TBAPF}_{6}\right)$ at $243 \mathrm{~K}$ (OTTLE cell). A) One-electron oxidation into the corresponding cation; B): one-electron oxidation of the cation into the corresponding dication. C) One-electron oxidation of the dication into the corresponding trication. 
Figure 1

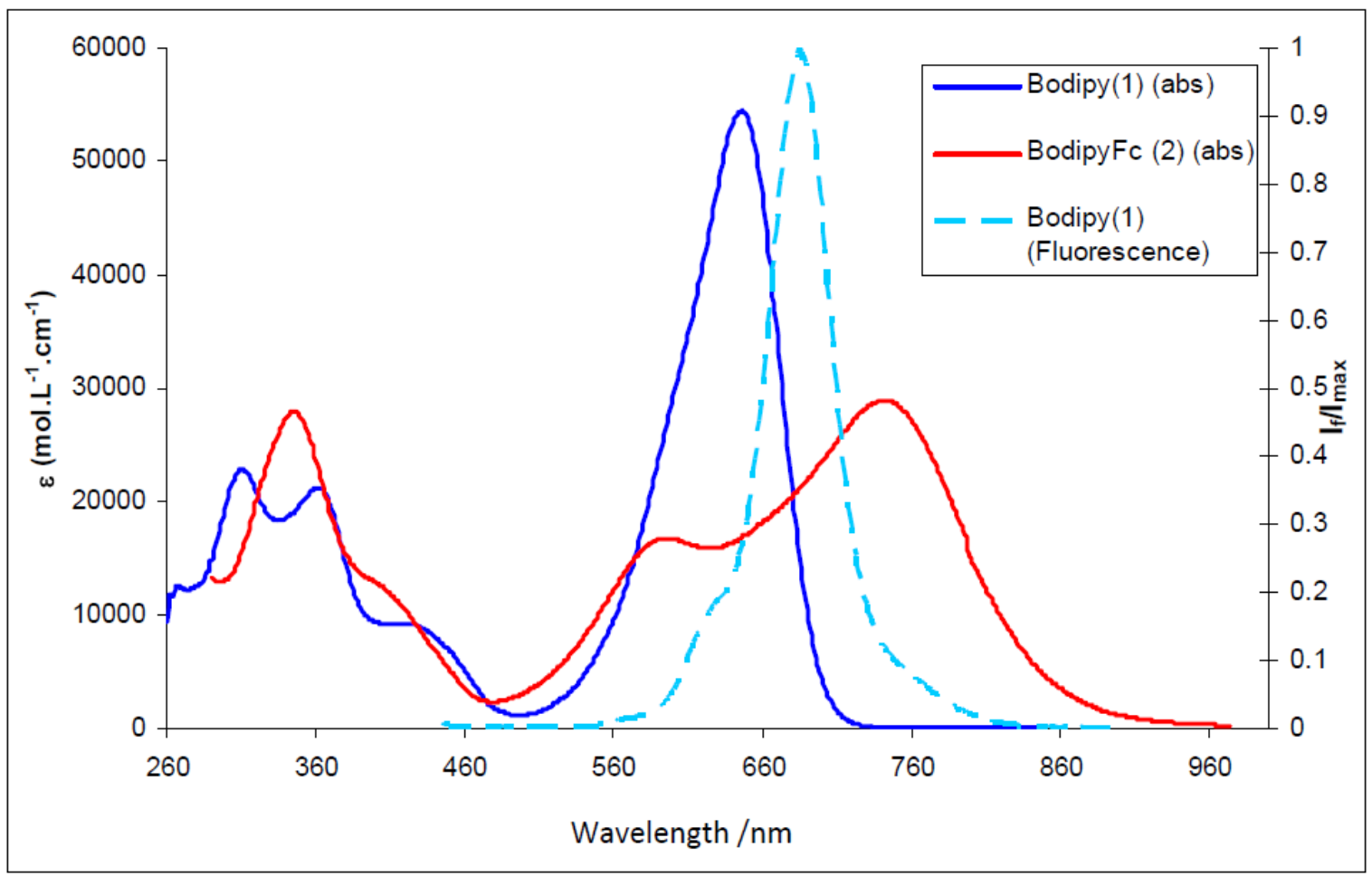


Figure 2

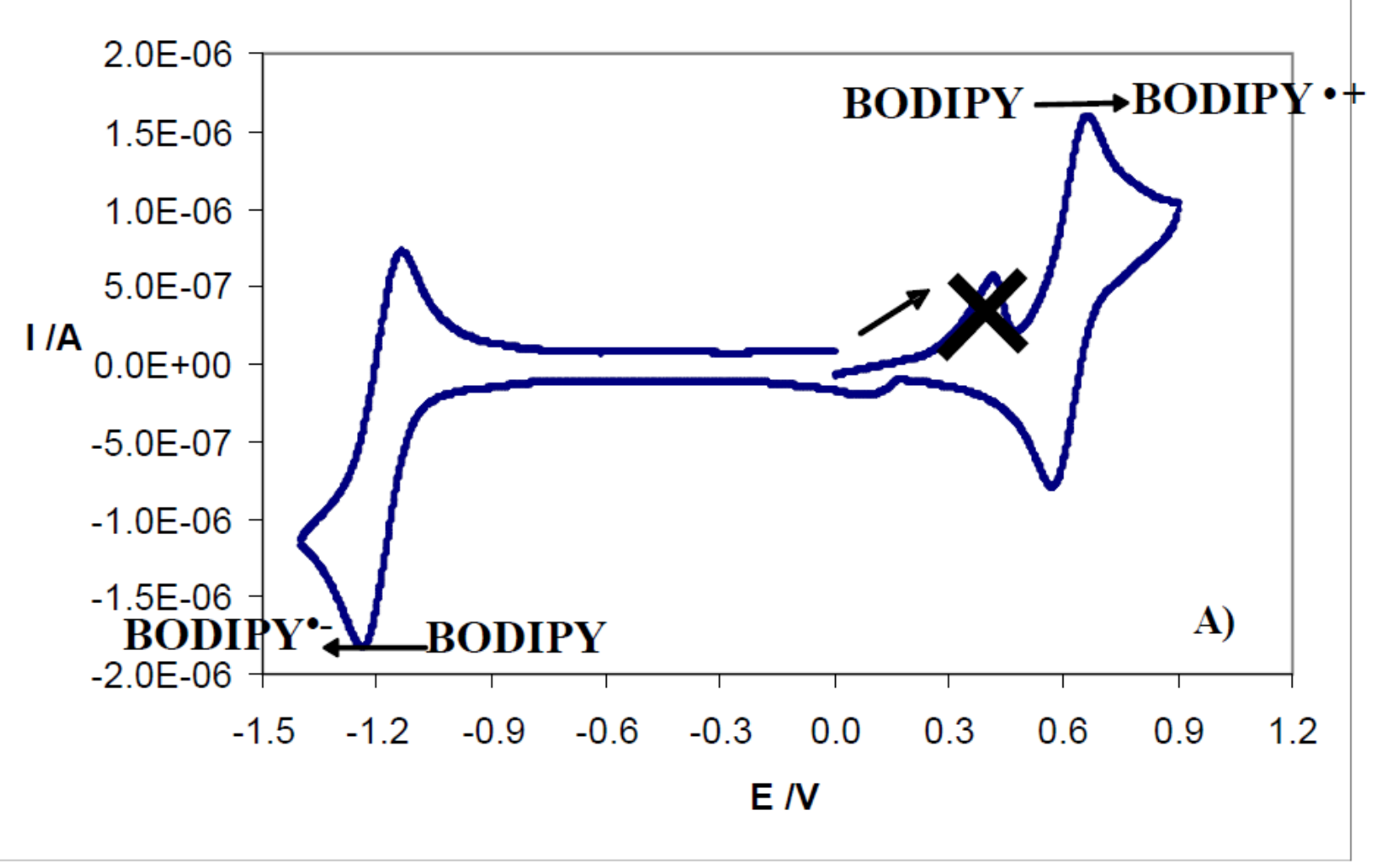



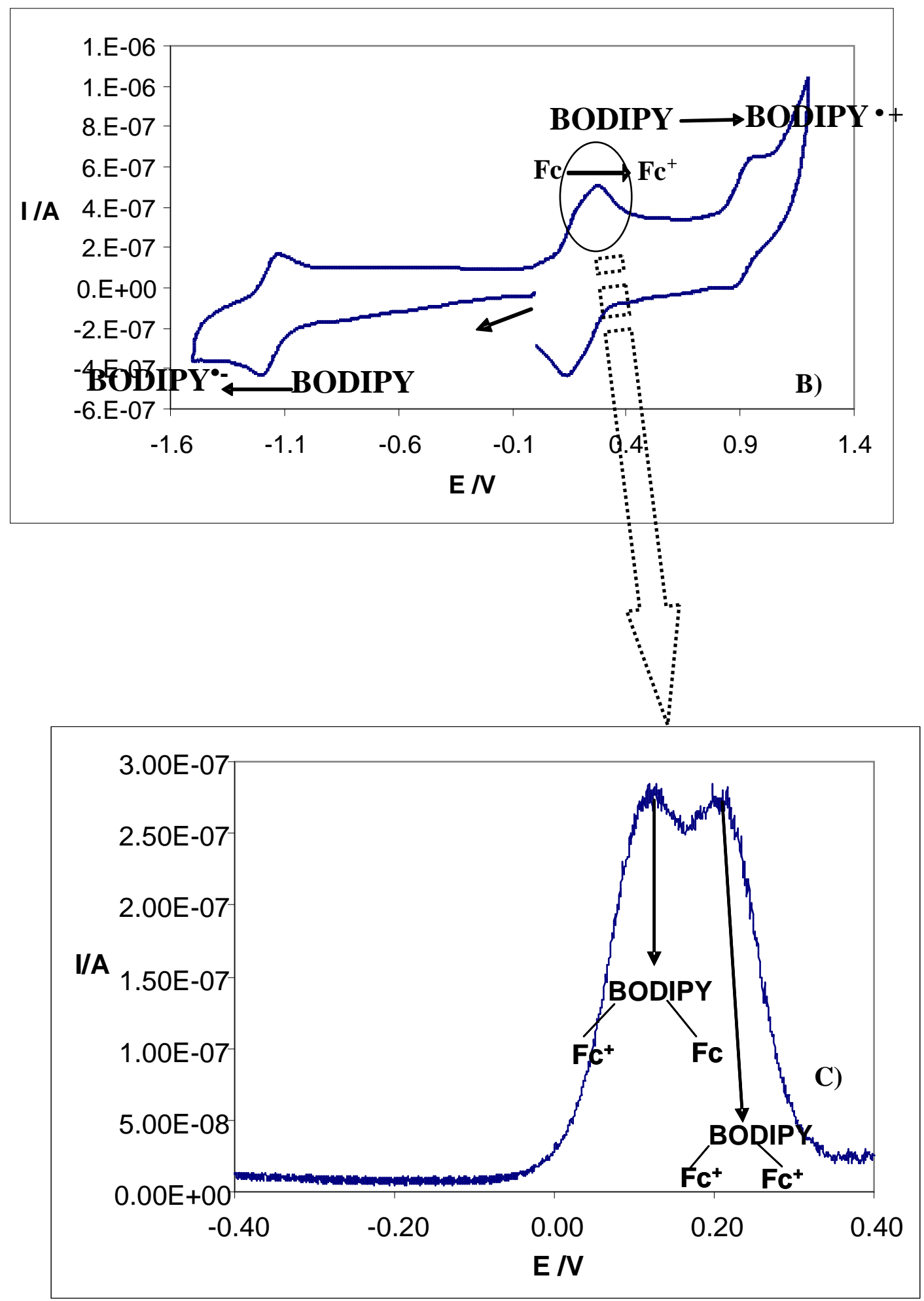
Figure 3

A)

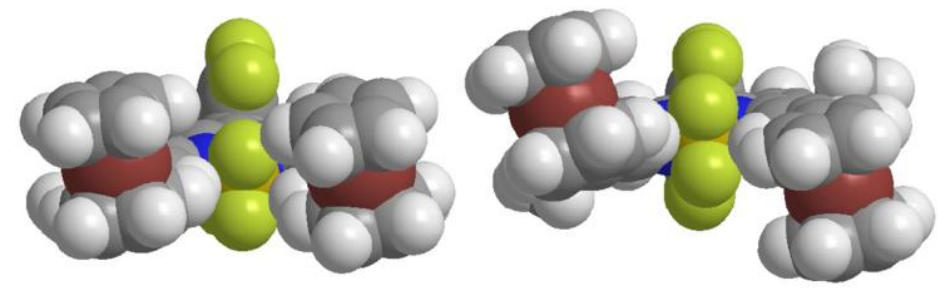

B)
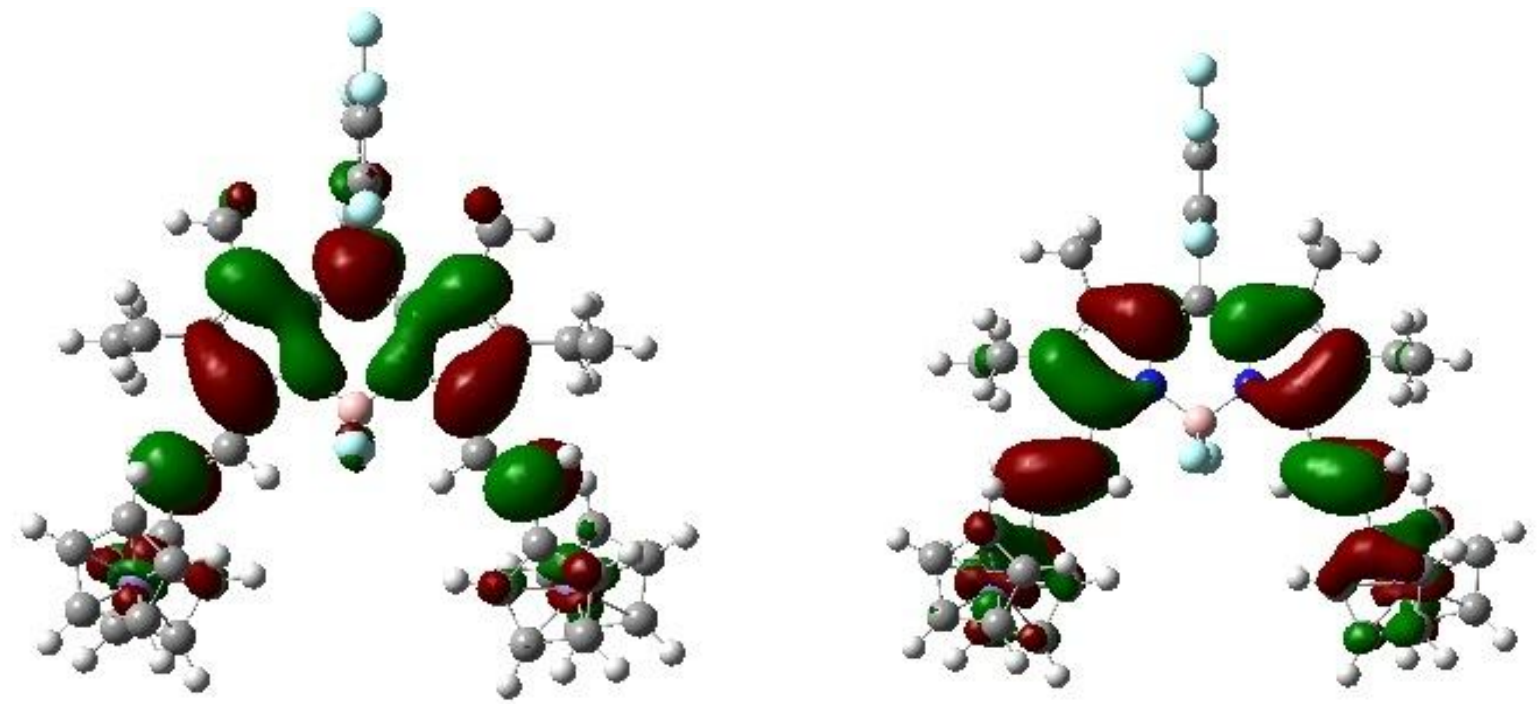

C)

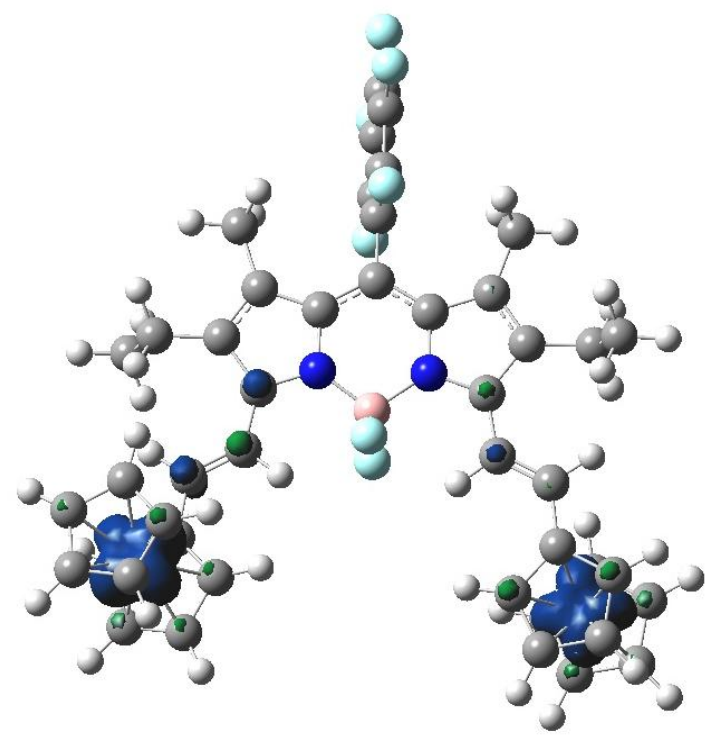


Figure 4
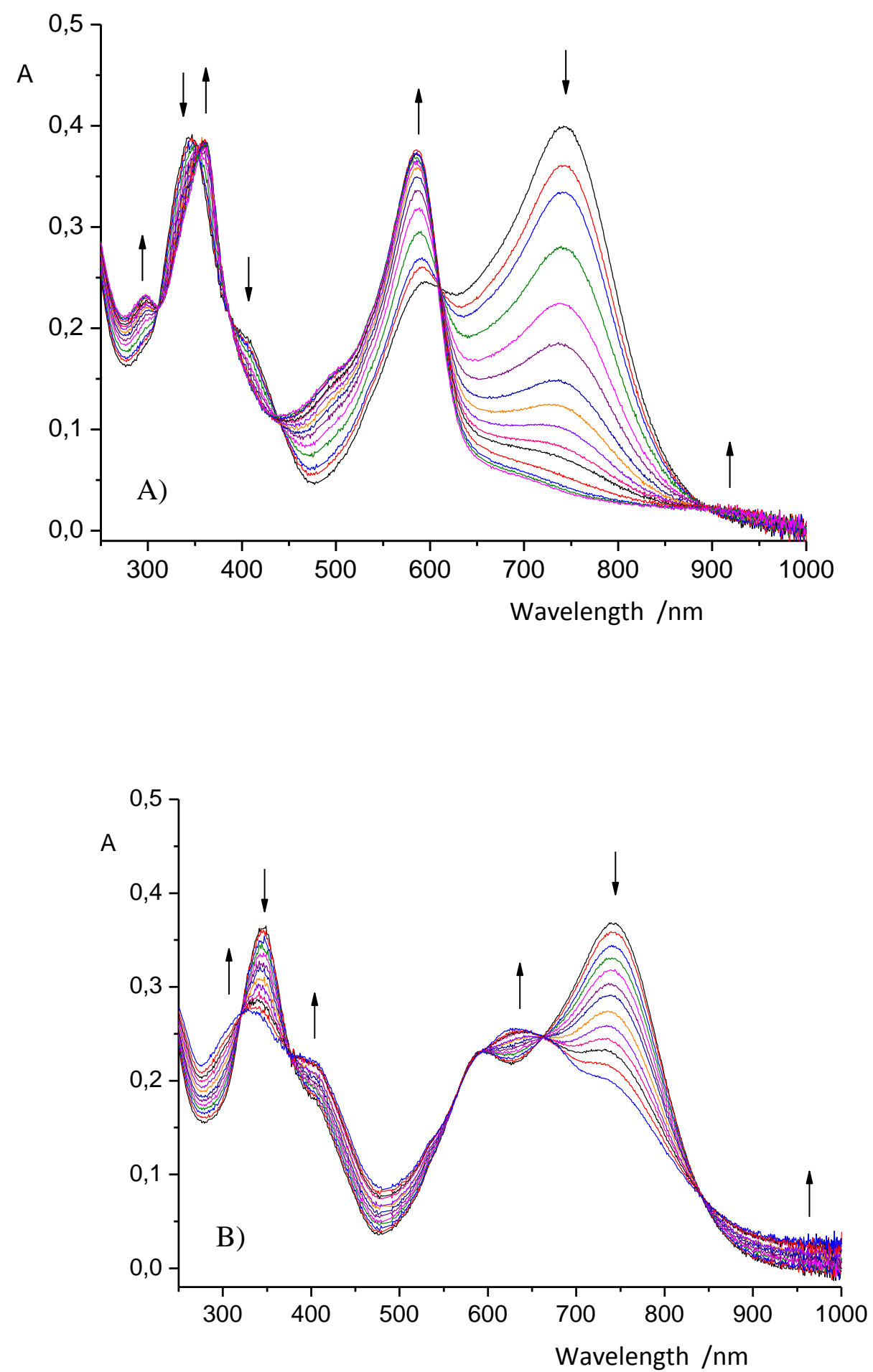

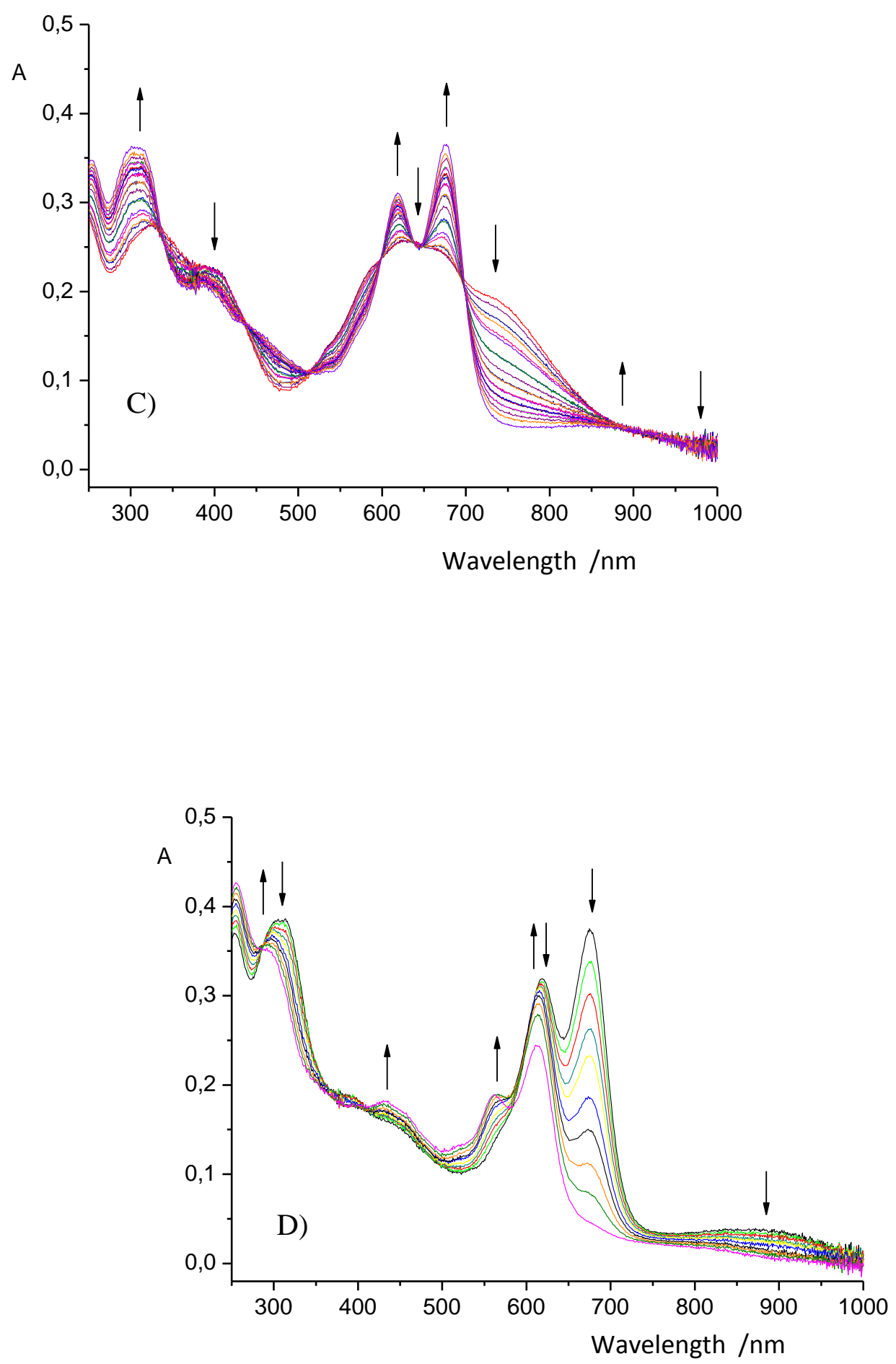
Figure 5

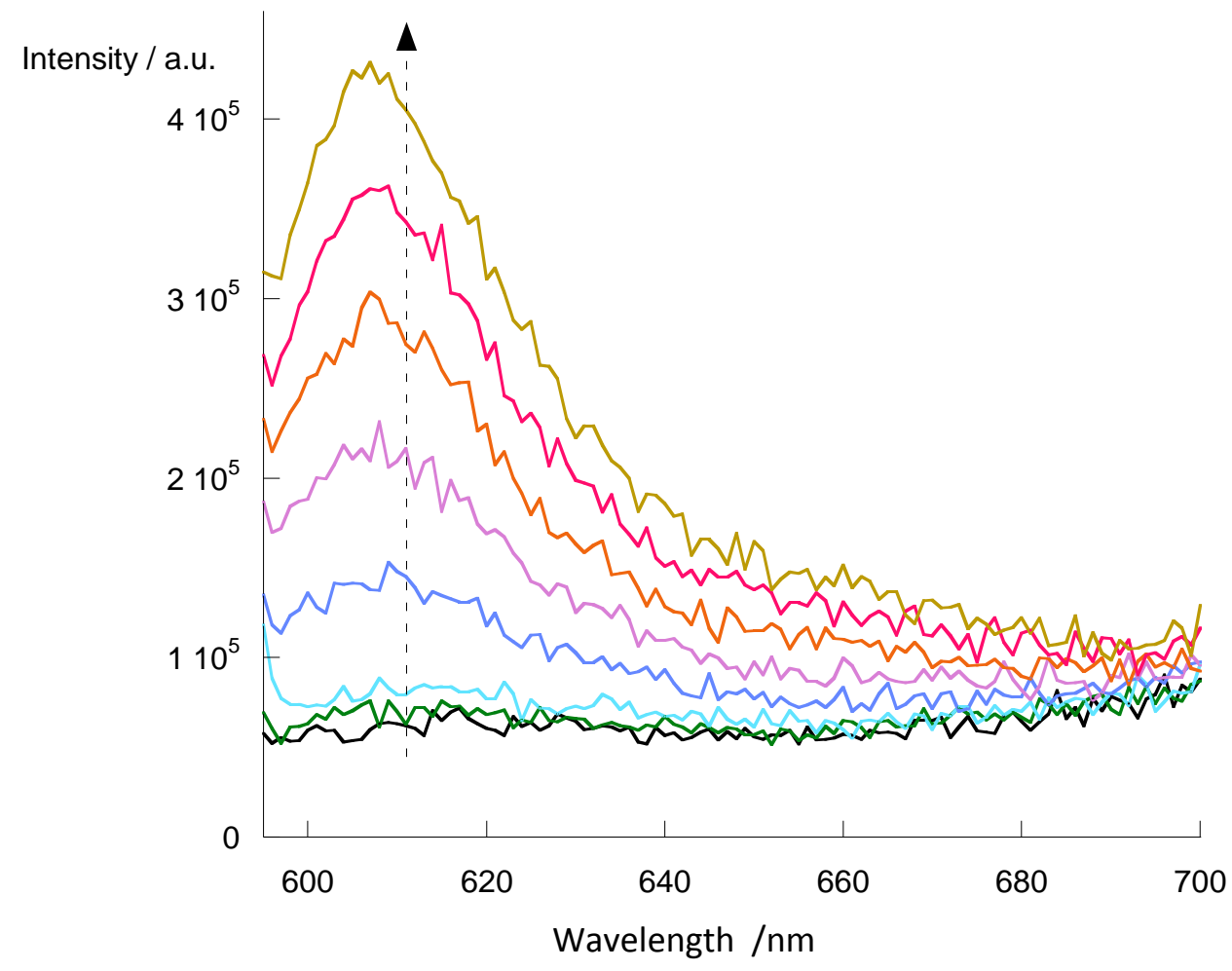


Figure 6
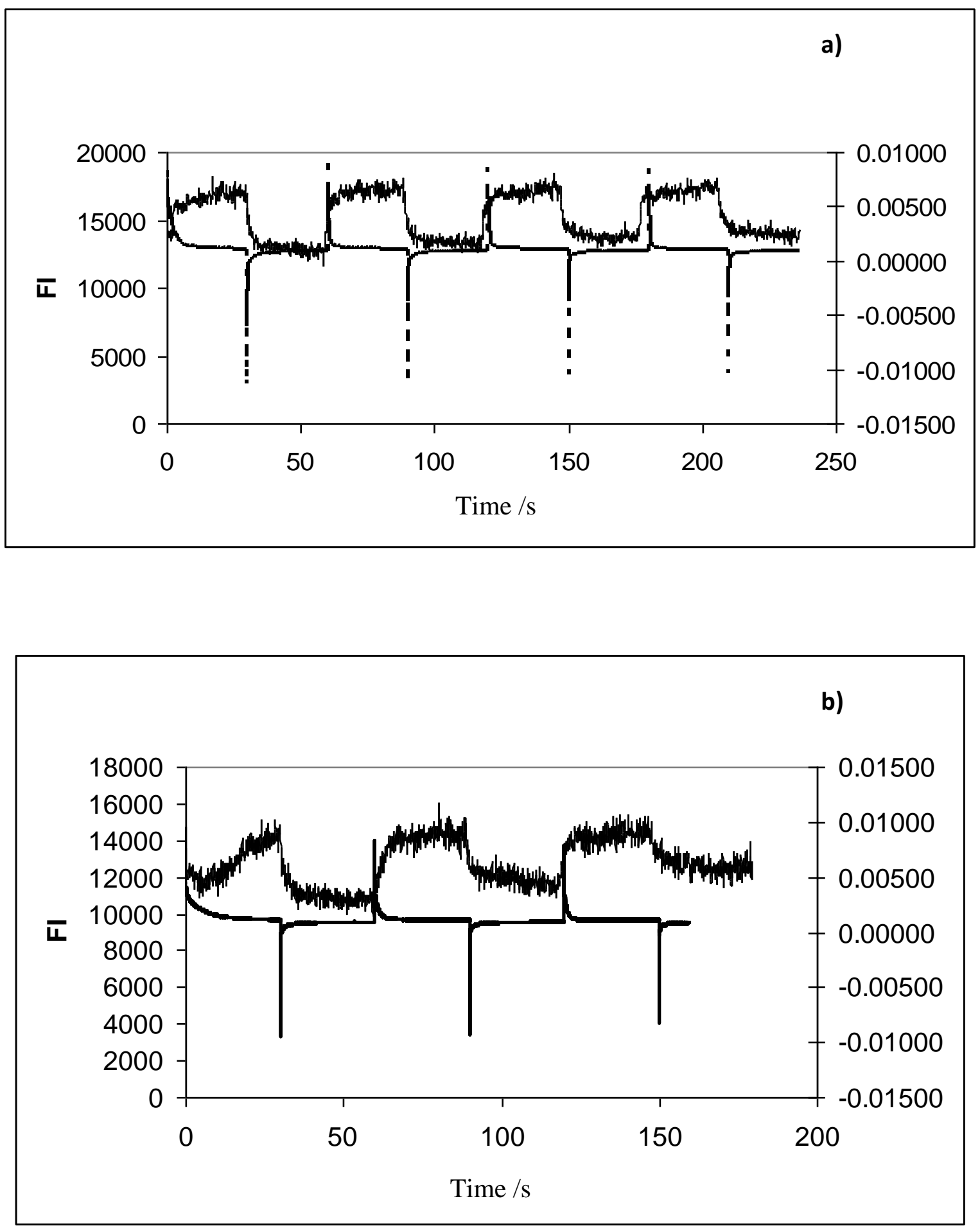
Figure 7

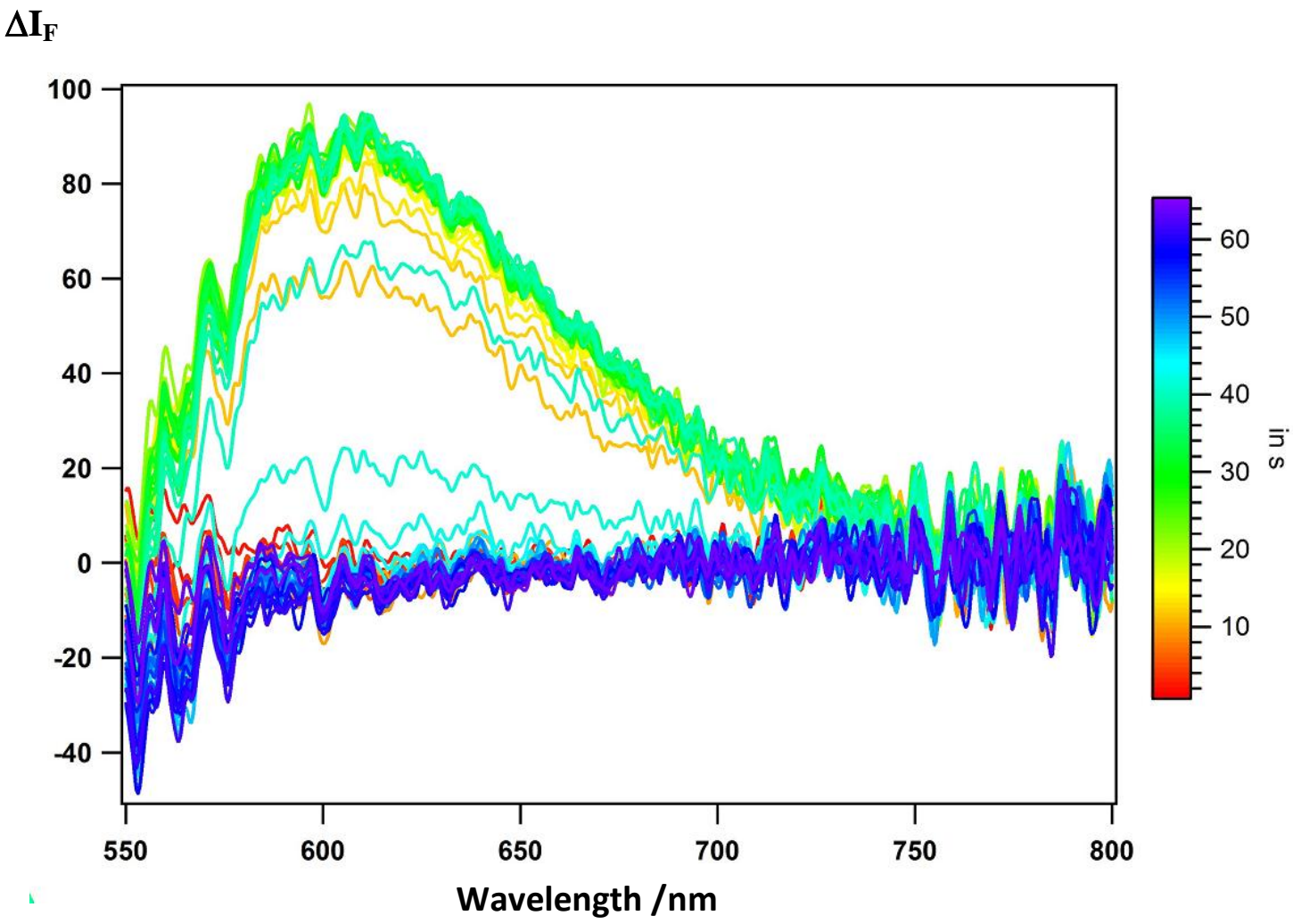


Supplementary Materials
Click here to download Supplementary Materials: Figure SI1 El Acta.doc

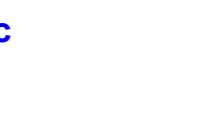

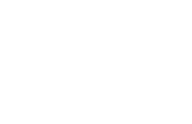

(a) 